\title{
Constitution of a comprehensive phytochemical profile and network pharmacology based investigation to decipher molecular mechanisms of Teucrium polium $L$. in the treatment of type 2 diabetes mellitus
}

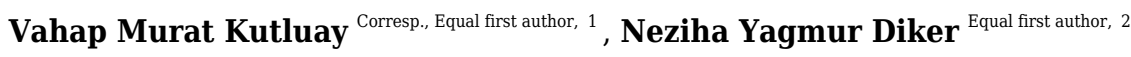 \\ 1 Faculty of Pharmacy Department of Pharmacognosy, Hacettepe University, Ankara, Turkey \\ ${ }^{2}$ Faculty of Pharmacy Department of Pharmaceutical Botany, Hacettepe University, Ankara, Turkey \\ Corresponding Author: Vahap Murat Kutluay \\ Email address: muratkutluay@hacettepe.edu.tr
}

Background. Type 2 diabetes mellitus (T2DM) is a metabolic disease affecting a huge population worldwide. Teucrium polium L. has been used as a folk medicine for the treatment of T2DM in Anatolia, Turkey. The antihyperglycemic effect of the plant was reported previously. However, there was no detailed study on the underlying molecular mechanisms. In this study, we generated a research plan to clarify the active constituents of the extract and uncover the molecular mechanisms using network pharmacology analysis.

Methods. For this purpose, we composed a dataset of 126 compounds for the phytochemical profile of the aerial parts of $T$. polium. Drug-likeness of the compounds was evaluated, and 52 compounds were selected for further investigation. 252 T2DM related targets hit by selected compounds were subjected to DAVID database.

Results. The KEGG pathway analysis showed enrichment for TNF signaling pathway, insulin resistance, HIF-1 signaling pathway, apoptosis, PI3K-AKT signaling pathway, FOXO signaling pathway, insulin signaling pathway, and type 2 diabetes mellitus which are related to T2DM . AKT1, IL6, STAT3, TP53, INS, and VEGFA were found to be key targets in protein-protein interaction. Besides these key targets, with this study the role of GSK3 $\beta$, GLUT4, and PDX1 were also discussed through literature and considered as important targets in the antidiabetic effect of $T$. polium. Various compounds of $T$. polium were shown to interact with the key targets activating PI3K-AKT and insulin signaling pathways.

Conclusions. According to these findings, mainly phenolic compounds were identified as the active components and IRS1/PI3K/AKT signaling and insulin resistance were identified as the main pathways regulated by $T$. polium. This study reveals the relationship of the compounds in $T$. polium with the targets of T2DM in human. Our findings suggested the use of $T$. polium as an effective herbal drug in the treatment of T2DM and provides new insights for further research on the antidiabetic effect of T. polium . 
1 Constitution of a comprehensive phytochemical

2 profile and network pharmacology based investigation

3 to decipher molecular mechanisms of Teucrium

4 polium $L$. in the treatment of type 2 diabetes mellitus 5

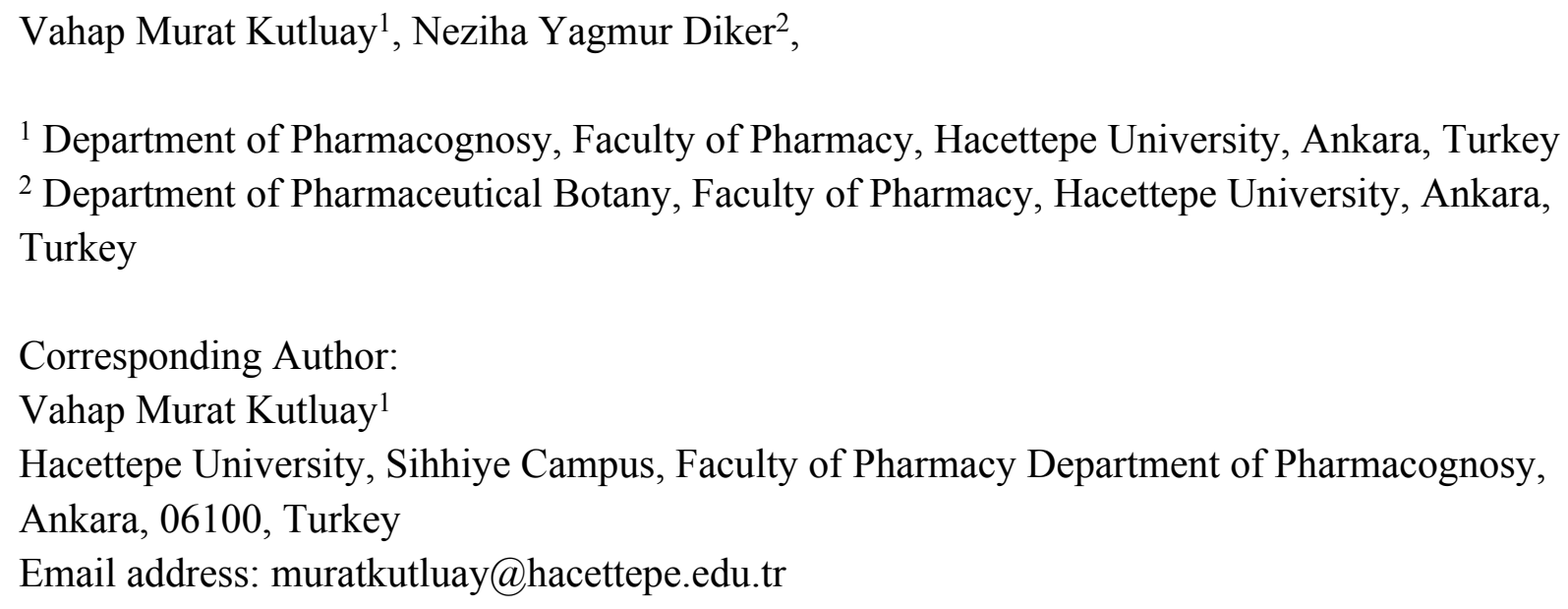




\section{Abstract}

42 Background. Type 2 diabetes mellitus (T2DM) is a metabolic disease affecting a huge

43 population worldwide. Teucrium polium L. has been used as a folk medicine for the treatment of

44 T2DM in Anatolia, Turkey. The antihyperglycemic effect of the plant was reported previously.

45 However, there was no detailed study on the underlying molecular mechanisms. In this study, we

46 generated a research plan to clarify the active constituents of the extract and uncover the

47 molecular mechanisms using network pharmacology analysis.

48 Methods. For this purpose, we composed a dataset of 126 compounds for the phytochemical

49 profile of the aerial parts of T. polium. Drug-likeness of the compounds was evaluated, and 52

50 compounds were selected for further investigation. 252 T2DM related targets hit by selected

51 compounds were subjected to DAVID database.

52 Results. The KEGG pathway analysis showed enrichment for TNF signaling pathway, insulin

53 resistance, HIF-1 signaling pathway, apoptosis, PI3K-AKT signaling pathway, FOXO signaling

54 pathway, insulin signaling pathway, and type 2 diabetes mellitus which are related to T2DM.

55 AKT1, IL6, STAT3, TP53, INS, and VEGFA were found to be key targets in protein-protein

56 interaction. Besides these key targets, with this study the role of GSK3 $\beta$, GLUT4, and PDX1

57 were also discussed through literature and considered as important targets in the antidiabetic

58 effect of T. polium. Various compounds of T. polium were shown to interact with the key targets

59 activating PI3K-AKT and insulin signaling pathways.

60 Conclusions. According to these findings, mainly phenolic compounds were identified as the

61 active components and IRS1/PI3K/AKT signaling and insulin resistance were identified as the

62 main pathways regulated by $T$. polium. This study reveals the relationship of the compounds in

63 T. polium with the targets of T2DM in human. Our findings suggested the use of T. polium as an

64 effective herbal drug in the treatment of T2DM and provides new insights for further research on

65 the antidiabetic effect of T. polium.

66

\section{Introduction}

68 Diabetes mellitus is a metabolic disease characterized by high blood glucose levels. According to the reports of WHO, about 422 million people live with diabetes. Diabetes was a direct cause of about 1.6 million deaths only in 2016. Among adults, $90 \%$ of the patients have type 2 diabetes mellitus (T2DM) (Holman et al. 2015). In T2DM, $\beta$-cell dysfunction and/or insulin resistance results with hyperglycemia and high glucose levels in blood. Patients with T2DM are under risk for some complications that diabetes can cause such as cardiovascular disease, renal disease, diabetic retinopathy and neuropathy (Zheng et al. 2018). In T2DM, multitarget treatment is used to overcome the defects caused in the organism (He et al. 2019; Vuylsteke et al. 2015). The genus Teucrium L., a member of Lamiaceae family (Subfamily Ajugoideaea), has a cosmopolitan distribution and including about 250 species spread worldwide (Stevens 2017). In Turkey, Teucrium polium L. is known as "Acıyavşan" and used as a traditional medicine for the treatment of diabetes (Arituluk \& Ezer 2012). In Algeria and Iran, T. polium is used traditionally 
81 aerial parts is used frequently for the treatment of diabetes, stomachache, hemorrhoid, common 82 colds, abdominal pains, antipyretics, and sunstroke as internally (Tuzlac1 2016). T. polium has 83 been shown to have mainly flavonoids, phenolic acids, phenylethanoid glycosides, and 84 terpenoids mainly diterpenoids (Bahramikia \& Yazdanparast 2012). Phytotherapeutic effects of 85 T. polium, such as antioxidant, antimutagenic, cytotoxic, anticancer, hepatoprotective, anti86 inflammatory, hypolipidemic, hypoglycemic, antinociceptive, antispasmodic, antiulcer, 87 antibacterial, antiviral, and antifungal activities have been shown by in vivo or in vitro assays 88 (Bahramikia \& Yazdanparast 2011; Hasani-Ranjbar et al. 2010).

89 The hypoglycemic effect of T. polium was shown by several reports (Esmaeili \& Yazdanparast 90 2004; Gharaibeh et al. 1988; Shahraki et al. 2007; Yazdanparas et al. 2005). The hypoglycemic 91 92

93 94 95 96 97 98 99 100

101

102

103

104

105

106

107

108

109

110

111

112

113

114

115

116

117

118

119 effect of T. polium was observed by Gharaibeh et. al. (1998) for the first time. In the research, the decoction of aerial parts was tested through three different administrations (oral, intraperitoneal, and intravenous) in normoglycemic and streptozotocin-induced hyperglycemic rats. In all administration ways of $T$. polium decoction, it had caused a decrease in blood glucose concentration. The decoction of T. polium had a decrease of $20.5 \%$ in blood glucose concentration by oral administration while intraperitoneal and intravenous administration of the decoction had a decrease of $26.5 \%$ and $44 \%$, respectively. The study has suggested that the hypoglycemic effect of $T$. polium was a result of an increase in the peripheral utilization of glucose (Gharaibeh et al. 1988). In another study, administration of ethanol-water (7:3) extract of aerial parts of T. polium per six weeks, resulted in a decrease of $64 \%$ in blood glucose levels of streptozocin-induced hyperglycemic rats. The result of this study also had proved that $T$. polium extract reduced blood glucose concentration by increasing pancreatic insulin secretion dosedependently (Esmaeili \& Yazdanparast 2004). Although there are reports about the hypoglycemic effect of $T$. polium, there is still a lack of information for underlying mechanisms. In a recent study, to elucidate molecular mechanisms, effects of $T$. polium extract on pancreatic islets cells regeneration was investigated. It was found that the antidiabetic effect of $T$. polium was connected with the antioxidant defense system and Pdx 1 expression in the JNK pathway (Tabatabaie \& Yazdanparast 2017).

Plants have been used for the treatment of various diseases in folk medicine. These herbal preparations consist of multiple compounds that target multiple proteins in an organism. This suits well with the multicomponent-multitarget paradigm (Zhang et al. 2019). Network pharmacology provides information to understand the underlying mechanisms of therapeutic and adverse effects of these multicomponent therapeutics (Hopkins 2008; Keith et al. 2005; Li \& Zhang 2013). Unlike the trend in drug research studies held in the 20th century which aims single components affecting single targets, nowadays researchers focus on multicomponent therapeutics. Network pharmacology is a rising trend in the 21 st century, mainly after $2010(\mathrm{Lu}$ et al. 2019). Network pharmacology studies revealed molecular mechanisms of several Traditional Chinese Medicine (TCM) recipes in the treatment of complex diseases already (Chen et al. 2019; Chen et al. 2018; Xiang et al. 2019). 
120 In this study, the underlying mechanisms of $T$. polium in the treatment of diabetes were aimed to 121 be elucidated. For this purpose, firstly the phytochemical content of the plant was screened

122 through a detailed literature search. Compounds reported from T. polium were selected based on 123 their drug-likeness properties and screened for their potential targets that play a role in the 124 biological processes. Therapeutical targets of T2DM and targets of the compounds were merged 125 for further investigations. Protein-protein interaction (PPI) network of common targets was

126

127

128

129

130

131

132

133

134

135

136

137

138

139

140

141

142

143

144

145

146

147

148

149

150

151

152

153

154

155

156

157

158

159 constructed. Key targets were determined and the role of targets in T2DM pathways was discussed.

\section{Materials \& Methods}

Literature based search for phytochemical content of T. polium

Previous phytochemical studies on T. polium were reviewed and compounds that were isolated or determined listed. Literature search was performed using 'Scopus' and 'Web of Science Clarivate' databases with the keyword 'Teucrium polium' upto June 2020. After the review process, it was found that 126 compounds were reported from T. polium by several reports. Due to their structure, compounds were listed under 3 groups (phenolics, terpenoids and amino acid derivatives). All the compounds were converted to Canonical SMILES format using PubChem (https://pubchem.ncbi.nlm.nih.gov/) or CS Chemdraw Ultra.

\section{Evaluation of drug likeness of the compounds}

The absorption and permeation abilities of the compounds in the extract play a critical role in the biological activity observed. In this study, Lipinski's rule of five was used to filter compounds which possess good absorption and permeation so that could be a new drug candidate. According to this criteria compounds which have; i) molecular weight (MW) greater than 500, ii) the calculated $\log \mathrm{P}$ value above 5 , iii) more than 5 hydrogen bond donors (HBD) and iv) more than 10 hydrogen bond acceptors (HBA) were filtered (Lipinski et al. 2001; Turner \& AgatonovicKustrin 2007). All 126 compounds were subjected to SWISSADME to obtain data for pharmacokinetics and drug-likeness (Daina et al. 2017). 52 compounds meet the 'Lipinski's rule of 5' and further used to construct 'Compound-Target' network. The detailed results for all the dataset of 126 compounds can be found in Table S1.

Construction of 'Compound-Target' network

In an herbal extract, each compound has an interaction with specific targets. The biological effects of the extract are a result of these interactions. Targets of the selected 52 compounds were searched through TCSMP (Traditional Chinese Medicine Systems Pharmacology Database and Analysis Platform), and SYMMAP databases (Ru et al. 2014; Wu et al. 2018). Compounds were also subjected to Swiss TargetPrediction for target fishing (Daina et al. 2019). During these screening, targets were limited for Homo sapiens. To avoid confusion, targets obtained were screened for UniprotKB ID for their unique identifiers (http://www.uniprot.org/) (Consortium 2018). Duplicate targets for the same compounds were removed and 'Compound-Target' 
160

161

162

163

164

165

166

167

168

169

170

171

172

173

174

175

176

177

178

179

180

181

182

183

184

185

186

187

188

189

190

191

192

193

194

195

196

197

198

199

network was obtained including 704 targets (Table S2). Cytoscape 3.8.0 was used for the visualization of the network (Shannon et al. 2003).

Collection of T2DM targets and network construction

T2DM related genes were collected from DisGeNET (https://www.disgenet.org/). 'Type 2 diabetes mellitus' was used as a keyword. DisGeNET is a platform with collections of genes associated with diseases (Bauer-Mehren et al. 2010). 1513 genes related to T2DM were obtained. The data obtained were transferred to Cytoscape 3.8.0.

'Compound-Target-Disease' network and the 'Protein-Protein Interaction' network construction For further investigation, the intersection of 'Compound-Target' network and T2DM related genes were set as 'Compound-Target-Disease' network. This network consisted of 252 genes (Table S3). For an illustration of the roles of selected genes in biological systems, the STRING database (http://string-db.org/, version 11) was used. STRING is a database that helps understanding associations between expressed proteins in a cellular function (Szklarczyk et al. 2018). Protein-protein interaction (PPI) map of 252 genes were generated. The confidence score was set as high $(>0.7)$. The key targets were defined using topological analysis. Topological network parameters cover some properties such as; degree distributions, stress centrality, betweenness centrality, closeness centrality (Doncheva et al. 2012). In this study, degree distributions were selected to identify key targets.

Gene enrichment analysis

DAVID Bioinformatics Resources 6.8 was used in gene enrichment analysis. DAVID database integrates biological knowledge with analytical tools that provide bioinformatic annotations (Huang et al. 2008; Huang et al. 2009). The 252 genes which were common for compounds and disease were uploaded to DAVID (https://david.ncifcrf.gov/). The results were listed based on their $p$ values. Top 20 results with lower $p$ value were selected. The results of gene ontology (GO) function and (Kyoto Encyclopedia of Genes and Genomes) KEGG pathway analysis were evaluated and discussed (Ashburner et al. 2000; Consortium 2019; Mi et al. 2019).

Construction of 'Compound-Target-Pathway' network

'Compound-Target-Disease' network and selected KEGG pathways were intersected to give 'Compound-Target-Pathway' network. Cytoscape was used for visualization.

\section{Results}

Screening of chemical compounds in T. polium and selection for the potential active compounds Through a detailed literature search, 126 compounds were listed in the aerial parts of T. polium (Table S4). Mainly phenolic compounds (flavonoids, phenylethanoid glycosides, phenolic acids), terpenoids (secoiridoids, iridoids, sesquiterpenoids, diterpenoids, triterpenoids) and amino acid derivatives (cyanogenic glycosides) were identified. Drug-likeness of these compounds were 
200

201

202

203

204

205

206

207

208

209

210

211

212

213

214

215

216

217

218

219

220

221

222

223

224

225

226

227

228

229

230

231

232

233

234

235

236

237

238

scanned through Lipinski's rule of 5 (the parameters of the compounds were given in Table S1). 80 compounds that met the selected criteria were searched for their potential targets using SYMMAP, TCMSP and Swiss Target Prediction databases. The databases provided information for 52 compounds (Table 1).

Analysis of compound-target interactions and determination of the common targets of T. polium and $\mathrm{T} 2 \mathrm{DM}$ related genes

There is a total of 704 genes related to 52 compounds. The 'Compound-Target' network consists of 756 nodes and 4023edges. Quercetin, apigenin and luteolin were found to be in relation with more targets than the other compounds (edge numbers were 254, 184 and 158 respectively). For further investigation, the common targets for T. polium and T2DM were determined. Firstly, 1513 T2DM related genes were imported from DisGeNet. All the targets were converted to Uniprot IDs to avoid confusion. The merge process of compound-target network and diseasetarget network resulted in 252 common targets (Fig. 1). These targets were selected for further investigation to understand the mechanisms of T. polium in the treatment of T2DM.

Construction of PPI networks and determination of the key targets

To understand the metabolic processes, PPIs play a key role. It comprises a network including direct and indirect interactions between proteins which give researchers new insights in understanding biological phenomena (Ijaz et al. 2018; Szklarczyk et al. 2018). To clarify the key targets in the 'Compound-Target-Disease' network, the target genes were subjected to STRING 11.0 using a confidence score of $>0.7$ (high) to achieve PPI network. The PPI network had 252 nodes and 1912 edges. According to topological analysis, degree distributions were evaluated. Degree shows the interaction numbers of the targets within the network. The nodes with a higher degree are referred to as a hub. The hub plays a key role in the biological process as it is related with more targets. Two-fold of the mean of the degree was selected as a threshold for the determination of key targets. 37 targets with a higher degree than 30.3 was thought to have a critical role for the mechanism of action (AKT1, INS, VEGFA, IL6, TP53, STAT3, MAPK1, APP, TNF, MAPK8, CXCL8, EGFR, PIK3CA, PIK3R1, SRC, MMP9, IL10, PTGS2, IL1B, CCL2, RELA, HRAS, GAPDH, PTEN, IL2, IL4, MTOR, TLR4, CASP3, JAK2, ICAM1, ESR1, FGF2, CXCL10, PPARG, MMP2, MAPK14). Acacetin (TP4), apigenin (TP5), jaceosidin (TP12), luteolin (TP13), quercetin (TP14), and caffeic acid (TP15) showed higher interactions with the key targets and might have a role in the antidiabetic effects of T. polium (Fig. 2). PPI network for key targets had 37 nodes and 425 edges. Interleukin-6 (IL6), signal transducer and activator of transcription 3 (STAT3), mitogen-activated protein kinase 1 (MAPK1), insulin (INS), and vascular endothelial growth factor A (VEGFA) were the proteins with a higher number of interactions (Fig. 3).

Gene enrichment analysis using DAVID database for GO and KEGG 
239

240

241

242

243

244

245

246

247

248

249

250

251

252

253

254

255

256

257

258

259

260

261

262

263

264

265

266

267

268

269

270

271

272

273

274

275

276

277

278

252 common targets were subjected to DAVID database for gene enrichments. GO and KEGG gene enrichment results were put in order according to their $p$ values. GO enrichment results were given in three parts; molecular, biological, and cellular. Top 20 results for each analysis were plotted in a graph produced by Graphpad Prism 6 (Fig. 4, 5).

The results for GO analysis were evaluated through related terms option of DAVID database. According to biological process results; response to drug (GO:0042493), negative regulation of apoptotic process (GO:0043066) and positive regulation of transcription from RNA polymerase II promoter (GO:0045944) showed higher target numbers in count (Fig. 4). Negative regulation of apoptotic process, inflammatory response (GO:0006954), positive regulation of cell proliferation (GO:0008284), glucose homeostasis (GO:0042593) and glucose transport (GO:0015758) were found to be related with at least one of the KEGG pathways such as PI3KAkt signaling pathway (hsa04151), TNF signaling pathway (hsa04668), insulin resistance (hsa04931), insulin signaling pathway (hsa04910), FoxO signaling pathway (hsa04068), adipocytokine signaling pathway (hsa04920), AMPK signaling pathway (hsa04152) and type 2 diabetes mellitus (hsa04930). Molecular function results with higher target numbers were protein binding (GO:0005515), protein homodimerization activity (GO:0042803), and identical protein binding (GO:0042802) (Fig. 4). Kinase activity (GO:0016301) and insulin receptor substrate binding (GO:0043560) were found to be related to at least one of the KEGG pathways such as insulin resistance, insulin signaling pathway, FoxO signaling pathway, PI3K-Akt signaling pathway, and type 2 diabetes mellitus.

KEGG enrichment results supported these findings. Results of 252 common targets were listed as (related with T2DM); TNF signaling pathway, insulin resistance, apoptosis, HIF-1 signaling pathway, PI3K-Akt signaling pathway, FoxO signaling pathway, insulin signaling pathway and type 2 diabetes mellitus (Fig. 5). The top 20 results according to the $p$ values suggested that, compounds reported from $T$. polium might also leads new insights for the treatment of cancer (Table 2).

\section{Discussion}

The potent hypoglycemic effect of $T$. polium extract has been reported by several reports (Esmaeili \& Yazdanparast 2004; Gharaibeh et al. 1988; Tabatabaie \& Yazdanparast 2017; Yazdanparas et al. 2005). According to the study performed by Tabatabaie and Yazdanparast, $T$. polium extract lowered fasting blood glucose levels closely to the control group. In addition to the hypoglycemic effect, $T$. polium treated rats had lower triglyceride and cholesterol levels when compared with diabetic rats (Tabatabaie \& Yazdanparast 2017). These experimental data show the potential of $T$. polium as a promising herb in the treatment of T2DM.

According to the findings of this study, we are considering that $T$. polium show its antidiabetic effect via enhancing $\beta$-cell number and function and exhibiting insulin-like effect through PI3KAKT pathway. Previous reports performed on the extract and compounds of $T$. polium support our findings of the network pharmacology assisted analysis. According to the KEGG enrichment results in our study, 18 key targets take part in PI3K-AKT pathway and 11 key targets take part 
279 in insulin resistance pathway (Table 2). For this view, it is essential to understand the roles of 280 these pathways in T2DM.

281 T2DM is appeared owing to two fundamental defects that are insulin resistance and impaired $\beta$ 282 cell function which are caused by long-term hyperglycemia (Cheatham \& Kahn 1995). Insulin 283 resistance is characterized as reduced insulin sensitivity in the target tissue (like skeletal muscle, 284 liver, and adipose). It is connected with the pathogenesis of metabolic diseases like obesity, type 2852 diabetes, hypertension, cardiovascular diseases, and fatty liver disease (Draznin 2020). 286 INS, one of the hub genes in the PPI network in our study, regulates glucose metabolism and 287 ensure metabolic homeostasis. It also promotes glycogen synthesis, lipid metabolism, protein 288 synthesis and degradations, gene transcriptions, etc. (Cheatham \& Kahn 1995). Additionally, it is 289 an important regulator of pancreatic $\beta$-cells growth and proliferation through the 290 phosphatidylinositol 3-kinase (PI3K)/AKT (also known as protein kinase B-PKB) pathway 291 (Fujimoto \& Polonsky 2009).

292 Insulin receptor activation through insulin binding stimulates PI3K-AKT signaling pathway. 293 AKT is determined as one of the key targets in our study and 4'-O-methyl luteolin (TP2), 6294 hydroxy luteolin (TP3), apigenin (TP5), isoscutellarein (TP11), jaceosidin (TP12), luteolin

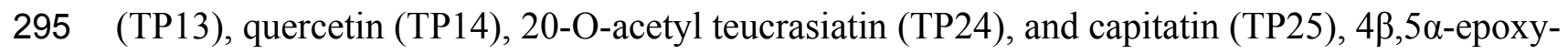
$2967 \alpha \mathrm{H}$-germacr-10(14)-en, $1 \beta$-hydroperoxyl,6 $\beta$-ol (TP36), $4 \alpha, 5 \beta$-epoxy-7 $\alpha \mathrm{H}$-germacr-10(14)297 en,1 $\beta$-hydroperoxyl,6 $\alpha$-ol (TP38), 5,3',4'- trihydroxy-3,7-dimethoxyflavone (TP47), jaranol 298 (TP48) showed interaction with the target AKT1 that could have a role in the antidiabetic effect 299 of T. polium (Fig. 2). AKT activation, promotes cell survival, proliferation, and growth by controlling key signaling nodes such as glycogen synthase kinase 3 (GSK3), Forkhead Box O (FoxO) transcriptions factors, tuberous sclerosis complex 2 (TSC2) and mechanistic target of rapamycin (mTOR) complex 1 (mTORC1) (Manning \& Toker 2017).

In a previous study about molecular mechanisms of the effects of T. polium extract on pancreatic $\beta$-cells regeneration, it was showed that c-jun N-terminal kinase (JNK) pathway provoked with oxidative stress leads to the inactivation of pancreas/duodenum homeobox protein 1 (PDX1) via FoxO1. In the same study, T. polium extract increased FoxO1 phosphorylation and, promoted the expression of PDX1 (Tabatabaie \& Yazdanparast 2017). Tyrosol (TP21), a polyphenol reported from T. polium, also was shown to inhibit ER-stress induced $\beta$-cell apoptosis by JNK phosphorylation (Lee et al. 2016). JNK pathway induces insulin receptor substrate 1 (IRS1) inhibition by causing serine phosphorylation which is an important step in downstream of insulin receptor signaling. This impairs the insulin signaling pathway by inhibiting IRS1-IRS2/PI3K-

312 AKT pathway (Kaneto et al. 2005). IRS1-IRS2/PI3K-AKT pathway inactivates FoxO1 which 313 supports pancreatic $\beta$-cells proliferation by enhancing PDX1 expression (Kitamura et al. 2002). 314 PDX1 has a very important role in pancreatic $\beta$-cell function and survival, is regulated through 315 FoxO1 and glycogen synthase kinase 3 beta (GSK3 $\beta$ ) (Fujimoto \& Polonsky 2009). In skeletal 316 muscle, AKT inactivates GSK3 $\beta$ by phosphorylation that results in a reduction in the 317 phosphorylation of a few GSK3 substrates such as Glycogen Synthase (GS) (Hermida et al. 318 2017). In pancreatic $\beta$-cells of the islets, GSK3 $\beta$ inhibited by AKT, does not phosphorylate 
319 PDX1. PDX1 is a critical regulator of pancreatic development and activates glucose transporter 2 320 (GLUT2), INS, and glucokinase genes (Humphrey et al. 2010). Thus, pharmacological inhibition 321 of GSK3 $\beta$ could be substantial in type 2 diabetes treatment (Sacco et al. 2019). Even GSK3 $\beta$ has 322 not been found as a key target in our PPI network, a large group of compounds reported in $T$. 323 polium interact with GSK3 $\beta$, listed as, 4',7-dimethoxy apigenin (TP1), 4'-O-methyl luteolin 324 (TP2), 6-hydroxy luteolin (TP3), acacetin (TP4), apigenin (TP5), cirsilineol (TP7), cirsiliol 325 (TP8), cirsimaritin (TP9), eupatorin (TP10), isoscutellarein (TP11), jaceosidin (TP12), luteolin 326 (TP13), quercetin (TP14), 20-O-acetyl teucrasiatin (TP24), capitatin (TP25), clerodane-6,7-dione

327

328

329

330

331

332

333

334

335

336

337

338

339

340

341

342

343

344

345

346

347

348

349

350

351

352

353

354

355

356

357

358 (TP26), (1R,6R,7R,8S,11R)-1,6-dihydroxy-4,11-dimethyl-germacran-4(5), 10(14)-dien-8,12olide (TP31), prunasin (TP33), teucladiol (TP40), $4 \beta, 6 \beta$-dihydroxy-1 $\alpha, 5 \beta(\mathrm{H})$-guai-9-ene (TP41), oplopanone (TP42), ladanein (TP45), salvigenin (TP46), 5,3',4'- trihydroxy-3,7dimethoxyflavone (TP47), jaranol (TP48) (Table S5). Both phenolic compounds, terpenoids and a cyanogenic glycoside found to interact with GSK3 $\beta$.

Furthermore, glucose transporter 4 (GLUT4) induction through insulin-stimulated PI3K/AKT has an important role in whole-body glucose homeostasis by glucose intake at adipose tissue, cardiomyocytes and skeletal muscle cells (Klip et al. 2019). Previous reports on flavonoids like apigenin (TP5), quercetin (TP14), kaempferol showed enhancement in GLUT4 translocation (Alkhalidy et al. 2015; Hossain et al. 2014; Jiang et al. 2019). According to the findings of our study, apigenin (TP5), luteolin (TP13), and quercetin (TP14) showed interaction with the target GLUT4 (Table S5). By Kadan et al. (2018), it was found that extract of $T$. polium increased translocation of GLUT4 in L6 muscle cells in the absence and presence of insulin when compared with the control. These findings indicated that insulin-like activity of $T$. polium is a result of increase in GLUT4 translocation (Kadan et al. 2018). Quercetin (TP14) and gallic acid (TP16) increased glucose uptake through IRS1/PI3K/AKT signaling (Gandhi et al. 2014; Jiang et al. 2019). Furthermore, it was shown that gallic acid and p-coumaric acid (TP17) ameliorate insulin shortage and insulin resistance (Abdel-Moneim et al. 2018). A previous study on rats showed that vanillic acid (TP19) upregulates hepatic insulin signaling, insulin receptor,

phosphatidylinositol-3 kinase, glucose transporter 2, and phosphorylated acetyl CoA carboxylase expression (Chang et al. 2015). Kaempferol treatment also showed to improve $\beta$-cell mass in diabetic mice (Alkhalidy et al. 2015). Similarly, cirsimaritin (TP9) suppresses apoptosis in $\beta$ cells (Lee et al. 2017).

IL6, another hub gene in the PPI network in this study, is a proinflammatory cytokine that has a complex role in T2DM. In this study, luteolin (TP13), quercetin (TP14) and teupolin VIII (TP29) showed interaction with the target IL6 (Table S5). Several studies showed that chronic inflammation plays a role in T2DM (Lehrskov \& Christensen 2019). Studies on the patients with T2DM showed an increase in IL6 levels in the plasma (Akbari \& Hassan-Zadeh 2018). The biological role of IL6 depends on the signaling pathway (Akbari \& Hassan-Zadeh 2018). Although there are different opinions on the effects of IL6 in T2DM, recent studies showed that the absence of IL6 resulted in hyperglycemia and higher fat levels in people with obesity (Kurauti et al. 2017; Lehrskov \& Christensen 2019). However, IL6 also increases the expression 
359

360

361

362

363

364

365

366

367

368

369

370

371

372

373

374

375

376

377

378

379

380

381

382

383

384

385

386

387

388

389

390

391

392

393

394

395

396

397

of insulin degrading enzyme which is important in glucose metabolism. This enzyme also degrades amyloid $\beta$. For this view, IL6 is an important cytokine both in two closely related diseases Alzheimer's disease and T2DM (Kurauti et al. 2017). STAT3 activation also negatively regulates another common target GSK3 $\beta$ of Alzheimer's disease and T2DM (Moh et al. 2008). STAT3 has a role in cell differentiation in various systems including immune and endocrine systems. However recent studies showed that STAT3 suppression together with Pdx1 expression increased the number of $\beta$-cells (Miura et al. 2018). Caffeic acid (TP15), t-ferulic acid (TP18), $4 \alpha$-[( $\beta$-D-glucopyranosyloxy)methyl]-5 $\alpha$-(2-hydroxyethyl)-3-methylcyclopent-2-en-1-one (TP22), 5 $\alpha$-[2-( $\beta$-D-glucopyranosyloxy)ethyl]-4 $\alpha$-hydroxymethyl-3-methylcyclopent-2-en-1-one (TP23), and teupolin VIII (TP29) showed interaction with the target STAT3 (Table S5). VEGFA is a growth factor that has an important role in angiogenesis, vasculogenesis and endothelial cell growth. Apigenin (TP5), luteolin (TP13), quercetin (TP14) and prunasin (TP33) showed interaction with the target VEGFA (Table S5). Hyperglycemic situations result in overexpression of VEGFA which is a critical factor in diabetic complications such as diabetic retinopathy (Caldwelll et al. 2003).

\section{Conclusions}

In the last decade, network pharmacology driven omics methods play an important role to understand the role of the herbal prescriptions used as a folk medicine in various diseases. In this study, molecular mechanisms of T. polium in the treatment of T2DM were evaluated with the help of bioinformatics. Though there were studies on T. polium extract's antihyperglycemic effect via in vitro and in vivo assays, the underlying molecular mechanisms has not totally determined yet. We constructed a comprehensive dataset of compounds reported in T. polium. 126 compounds previously isolated or determined from the aerial parts of the plant were listed through a detailed literature search. In this view, this study serves the most detailed data on the content of the phytochemical profile of T. polium so far.

In the present network pharmacological analysis, insulin resistance and PI3K-AKT signaling pathway were shown to take place in the center of the mechanism of action of T. polium. T. polium is an insulin-sensitizing plant. Even though insulin resistance has an important role in the pathophysiology of T2DM, insulin resistance does not result in T2DM in all cases. It turns to T2DM with a loss in $\beta$-cell mass in pancreatic islets. The results of the present network pharmacology studies taken together with the previously reported data, suggested that $T$. polium could be a promising herb for the treatment of T2DM through ameliorating insulin resistance and enhancing $\beta$-cell mass.

\section{Acknowledgements}

None.

\section{References}


398

399

400

401

402

403

404

405

406

407

408

409

410

411

412

413

414

415

416

417

418

419

420

421

422

423

424

425

426

427

428

429

430

431

432

433

434

435

436

437

Abdel-Moneim A, El-Twab SMA, Yousef AI, Reheim ESA, and Ashour MB. 2018. Modulation of hyperglycemia and dyslipidemia in experimental type 2 diabetes by gallic acid and pcoumaric acid: The role of adipocytokines and PPAR $\gamma$. Biomedicine \& Pharmacotherapy 105:1091-1097. DOI:10.1016/j.biopha.2018.06.096

Akbari M, and Hassan-Zadeh V. 2018. IL-6 signalling pathways and the development of type 2 diabetes. Inflammopharmacology 26:685-698. DOI:10.1007/s10787-018-0458-0 Alkhalidy H, Moore W, Zhang YL, McMillan R, Wang AH, Ali M, Suh KS, Zhen W, Cheng ZY, Jia ZQ, Hulver M, and Liu DM. 2015. Small molecule kaempferol promotes insulin sensitivity and preserved pancreatic beta-cell mass in middle-aged obese diabetic mice. Journal of Diabetes Research. Artn 532984. DOI:10.1155/2015/532984

Arıtuluk ZC, and Ezer N. 2012. Halk Arasında Diyabete Karşı Kullanılan Bitkiler Türkiye -II Hacettepe Üniversitesi Eczacılık Fakültesi Dergisi 32:179-208. Retrieved from https://dergipark.org.tr/en/pub/hujpharm/issue/49831/639072 Ashburner M, Ball CA, Blake JA, Botstein D, Butler H, Cherry JM, Davis AP, Dolinski K, Dwight SS, Eppig JT, Harris MA, Hill DP, Issel-Tarver L, Kasarskis A, Lewis S, Matese JC, Richardson JE, Ringwald M, Rubin GM, and Sherlock G. 2000. Gene Ontology: tool for the unification of biology. Nature Genetics 25:25-29. DOI:10.1038/75556

Bahramikia S, and Yazdanparast R. 2011. Phytochemistry and medicinal properties of Teucrium polium L. (Lamiaceae). Clinical Biochemistry 44:S336-S337.

DOI:10.1016/j.clinbiochem.2011.08.834

Bahramikia S, and Yazdanparast R. 2012. Phytochemistry and medicinal properties of Teucrium polium L. (Lamiaceae). Phytotherapy Research 26:1581-1593. DOI:10.1002/ptr.4617

Bauer-Mehren A, Rautschka M, Sanz F, and Furlong LI. 2010. DisGeNET: a Cytoscape plugin to visualize, integrate, search and analyze gene-disease networks. Bioinformatics 26:2924-2926. DOI:10.1093/bioinformatics/btq538

Caldwelll RB, Bartoli M, Behzadian MA, El-Remessy AEB, Al-Shabrawey M, Platt DH, and Caldwell RW. 2003. Vascular endothelial growth factor and diabetic retinopathy:

pathophysiological mechanisms and treatment perspectives. Diabetes-Metabolism Research and Reviews 19:442-455. DOI:10.1002/dmrr.415

Chang WC, Wu JSB, Chen CW, Kuo PL, Chien HM, Wang YT, and Shen SC. 2015. Protective Effect of vanillic acid against hyperinsulinemia, hyperglycemia and hyperlipidemia via alleviating hepatic insulin resistance and inflammation in high-fat diet (HFD)-fed rats. Nutrients 7:9946-9959. DOI:10.3390/nu7125514

Cheatham B, and Kahn CR. 1995. Insulin action and the insulin signaling network. Endocrine Reviews 16:117-142. DOI:10.1210/edrv-16-2-117

Chen C, Li HL, Yi Y, Fan HJ, and Chen C. 2019. Network pharmacology-based study on the active substances and mechanism of Nao An Capsule in treatment of ischemic stroke. European Journal of Integrative Medicine 31. ARTN 100976 DOI:10.1016/j.eujim.2019.100976 Chen LD, Cao Y, Zhang H, Lv D, Zhao YH, Liu YJ, Ye G, and Chai YF. 2018. Network pharmacology-based strategy for predicting active ingredients and potential targets of 
438 Yangxinshi tablet for treating heart failure. Journal of Ethnopharmacology 219:359-368.

439 DOI:10.1016/j.jep.2017.12.011

440 Chinsembu KC. 2019. Diabetes mellitus and nature's pharmacy of putative antidiabetic plants.

441 Journal of Herbal Medicine 15:100230. DOI:10.1016/j.hermed.2018.09.001

442 Consortium TGO. 2019. The Gene Ontology Resource: 20 years and still GOing strong. Nucleic

443 Acids Research 47:D330-d338. DOI:10.1093/nar/gky1055

444 Consortium TU. 2018. UniProt: a worldwide hub of protein knowledge. Nucleic Acids Research

445 47:D506-D515. DOI:10.1093/nar/gky1049

446 Daina A, Michielin O, and Zoete V. 2017. SwissADME: a free web tool to evaluate

447 pharmacokinetics, drug-likeness and medicinal chemistry friendliness of small molecules.

$448 \quad$ Scientific Reports 7. ARTN 42717. DOI:10.1038/srep42717

449 Daina A, Michielin O, and Zoete V. 2019. SwissTargetPrediction: updated data and new features

450 for efficient prediction of protein targets of small molecules. Nucleic Acids Research 47:W357-

451 W364. DOI:10.1093/nar/gkz382

452 Doncheva NT, Assenov Y, Domingues FS, and Albrecht M. 2012. Topological analysis and 453 interactive visualization of biological networks and protein structures. Nature Protocols 7:670-

454 685. DOI:10.1038/nprot.2012.004

455 Draznin B. 2020. Molecular Mechanisms of Insulin Resistance. In: Zeitler PS, and Nadeau KJ, 456 eds. Insulin Resistance. Cham: Springer International Publishing, 55-66. DOI:10.1007/978-3457 030-25057-7_4

458 Esmaeili MA, and Yazdanparast R. 2004. Hypoglycaemic effect of Teucrium polium: studies 459 with rat pancreatic islets. Journal of Ethnopharmacology 95:27-30.

460 DOI:10.1016/j.jep.2004.06.023

461 Fujimoto K, and Polonsky KS. 2009. Pdx1 and other factors that regulate pancreatic beta-cell

462 survival. Diabetes Obesity \& Metabolism 11:30-37. DOI:10.1111/j.1463-1326.2009.01121.x

463 Gandhi GR, Jothi G, Antony PJ, Balakrishna K, Paulraj MG, Ignacimuthu S, Stalin A, and Al-

464 Dhabi NA. 2014. Gallic acid attenuates high-fat diet fed-streptozotocin-induced insulin

465 resistance via partial agonism of PPAR $\gamma$ in experimental type 2 diabetic rats and enhances

466 glucose uptake through translocation and activation of GLUT4 in PI3K/p-Akt signaling pathway.

467 European Journal of Pharmacology 745:201-216. DOI:10.1016/j.ejphar.2014.10.044

468 Gharaibeh MN, Elayan HH, and Salhab AS. 1988. Hypoglycemic effects of Teucrium polium.

469 Journal of Ethnopharmacology 24:93-99. DOI:10.1016/0378-8741(88)90139-0

470 Hasani-Ranjbar S, Nayebi N, Larijani B, and Abdollahi M. 2010. A systematic review of the

471 efficacy and safety of Teucrium species, from anti-oxidant to anti-diabetic effects. International

472 Journal of Pharmacology 6:315-325. DOI: 10.3923/ijp.2010.315.325

473 He D, Huang JH, Zhang ZY, Du Q, Peng WJ, Yu R, Zhang SF, Zhang SH, and Qin YH. 2019. A

474 Network pharmacology-based strategy for predicting active ingredients and potential targets of

475 LiuWei DiHuang Pill in treating type 2 diabetes mellitus. Drug Design Development and

476 Therapy 13:3989-4005. DOI:10.2147/Dddt.S216644 
477 Hermida MA, Dinesh Kumar J, and Leslie NR. 2017. GSK3 and its interactions with the

$478 \mathrm{PI} 3 \mathrm{~K} / \mathrm{AKT} / \mathrm{mTOR}$ signalling network. Advances in Biological Regulation 65:5-15.

479 DOI:10.1016/j.jbior.2017.06.003

480 Holman N, Young B, and Gadsby R. 2015. Current prevalence of type 1 and type 2 diabetes in

481 adults and children in the UK. Diabetic Medicine 32:1119-1120. DOI:10.1111/dme.12791

482 Hopkins AL. 2008. Network pharmacology: the next paradigm in drug discovery. Nature

483 Chemical Biology 4:682-690. DOI:10.1038/nchembio.118

484 Hossain MC, Ghosh MK, Satapathy BS, Dey NS, and Mukherjee B. 2014. Apigenin causes

485 biochemical modulation, Glut4 and Cd38 alterations to improve diabetes and to protect damages

486 of some vital organs in experimental diabetes. American Journal of Pharmacology and

487 Toxicology 9:39-52. DOI:10.3844/ajptsp.2014.39.52

488 Huang DW, Sherman BT, and Lempicki RA. 2008. Bioinformatics enrichment tools: paths

489 toward the comprehensive functional analysis of large gene lists. Nucleic Acids Research 37:1-

490 13. DOI:10.1093/nar/gkn923

491 Huang DW, Sherman BT, and Lempicki RA. 2009. Systematic and integrative analysis of large

492 gene lists using DAVID bioinformatics resources. Nature Protocols 4:44-57.

493 DOI:10.1038/nprot.2008.211

494 Humphrey RK, Yu SM, Flores LE, and Jhala US. 2010. Glucose regulates steady-state levels of 495 PDX1 via the reciprocal actions of GSK3 and AKT kinases. Journal of Biological Chemistry

496 285:3406-3416. DOI:10.1074/jbc.M109.006734

497 Ijaz M, Ansari M-u-R, and Iqbal M. 2018. Introductory Chapter: Protein-Protein Interactions and 498 Assays. In: Ansari M-u-R, Protein-Protein Interaction Assays. IntechOpen.

499 DOI:10.5772/intechopen.77337

500 Jiang H, Yamashita Y, Nakamura A, Croft K, and Ashida H. 2019. Quercetin and its metabolite 501 isorhamnetin promote glucose uptake through different signalling pathways in myotubes.

502 Scientific Reports 9. ARTN 2690 DOI:10.1038/s41598-019-38711-7Kadan S, Sasson Y, Abu-

503 Reziq R, Saad B, Benvalid S, Linn T, Cohen G, and Zaid H. 2018. Teucrium polium extracts

504 stimulate GLUT4 translocation to the plasma membrane in L6 muscle cells. Advancement in

505 Medicinal Plant Research 6:1-8.

506 Kaneto H, Matsuoka T, Nakatani Y, Kawamori D, Miyatsuka T, Matsuhisa M, and Yamasaki Y.

507 2005. Oxidative stress, ER stress, and the JNK pathway in type 2 diabetes. Journal of Molecular

508 Medicine-Jmm 83:429-439. DOI:10.1007/s00109-005-0640-x

509 Keith CT, Borisy AA, and Stockwell BR. 2005. Multicomponent therapeutics for networked

510 systems. Nature Reviews Drug Discovery 4:71-78. DOI:10.1038/nrd1609

511 Kitamura T, Nakae J, Kitamura Y, Kido Y, Biggs WH, 3rd, Wright CV, White MF, Arden KC,

512 and Accili D. 2002. The forkhead transcription factor Foxo1 links insulin signaling to Pdx1

513 regulation of pancreatic beta cell growth. Journal of Clinical Investigation 110:1839-1847.

514 DOI:10.1172/jci16857

515 Klip A, McGraw TE, and James DE. 2019. Thirty sweet years of GLUT4. Journal of Biological

516 Chemistry 294:11369-11381. DOI:10.1074/jbc.REV119.008351 
517 Kurauti MA, Costa JM, Ferreira SM, Santos GJ, Sponton CHG, Carneiro EM, Telles GD, 518 Chacon-Mikahil MPT, Cavaglieri CR, Rezende LF, and Boschero AC. 2017. Interleukin-6 519 increases the expression and activity of insulin-degrading enzyme. Scientific Reports 7. ARTN 520 46750. DOI:10.1038/srep46750

521 Lee D, Kim KH, Lee J, Hwang GS, Lee HL, Hahm DH, Huh CK, Lee SC, Lee S, and Kang KS.

522 2017. Protective effect of cirsimaritin against streptozotocin-induced apoptosis in pancreatic beta 523 cells. Journal of Pharmacy and Pharmacology 69:875-883. DOI:10.1111/jphp.12719

524 Lee H, Im SW, Jung CH, Jang YJ, Ha TY, and Ahn J. 2016. Tyrosol, an olive oil polyphenol, 525 inhibits ER stress-induced apoptosis in pancreatic $\beta$-cell through JNK signaling. Biochemical 526 and Biophysical Research Communications 469:748-752. DOI:10.1016/j.bbrc.2015.12.036 527 Lehrskov LL, and Christensen RH. 2019. The role of interleukin-6 in glucose homeostasis and 528 lipid metabolism. Seminars in Immunopathology 41:491-499. DOI:10.1007/s00281-019-00747-2 529 Li S, and Zhang B. 2013. Traditional Chinese medicine network pharmacology: theory, 530 methodology and application. Chinese Journal of Natural Medicines 11:110-120.

531 DOI:10.1016/S1875-5364(13)60037-0

532 Lipinski CA, Lombardo F, Dominy BW, and Feeney PJ. 2001. Experimental and computational 533 approaches to estimate solubility and permeability in drug discovery and development settings 534 (Reprinted from Advanced Drug Delivery Reviews, vol 23, pg 3-25, 1997). Advanced Drug 535 Delivery Reviews 46:3-26. DOI:10.1016/S0169-409x(00)00129-0

536 Lu CC, Bing ZT, Bi ZJ, Liu M, Lu TT, Xun YQ, Wei ZP, and Yang KH. 2019. Top-100 most 537 cited publications concerning network pharmacology: a bibliometric analysis. Evidence-Based 538 Complementary and Alternative Medicine 2019. Artn 1704816 DOI:10.1155/2019/1704816 539 Manning BD, and Toker A. 2017. AKT/PKB signaling: navigating the network. Cell 169:381540 405. DOI:10.1016/j.cell.2017.04.001

541 Mi H, Muruganujan A, Ebert D, Huang X, and Thomas PD. 2019. PANTHER version 14: more 542 genomes, a new PANTHER GO-slim and improvements in enrichment analysis tools. Nucleic 543 Acids Research 47:D419-d426. DOI:10.1093/nar/gky1038

544 Miura M, Miyatsuka T, Katahira T, Sasaki S, Suzuki L, Himuro M, Nishida Y, Fujitani Y, 545 Matsuoka TA, and Watada H. 2018. Suppression of STAT3 signaling promotes cellular 546 reprogramming into insulin-producing cells induced by defined transcription factors.

547 Ebiomedicine 36:358-366. DOI:10.1016/j.ebiom.2018.09.035

548 Moh A, Zhang WJ, Yu S, Wang J, Xu XM, Li JL, and Fu XY. 2008. STAT3 sensitizes insulin 549 signaling by negatively regulating glycogen synthase kinase-3 beta. Diabetes 57:1227-1235.

550 DOI:10.2337/db06-1582

551 Rezaei A, Farzadfard A, Amirahmadi A, Alemi M, and Khademi M. 2015. Diabetes mellitus and

552 its management with medicinal plants: A perspective based on Iranian research. Journal of

553 Ethnopharmacology 175:567-616. DOI:10.1016/j.jep.2015.08.010

554 Ru JL, Li P, Wang JN, Zhou W, Li BH, Huang C, Li PD, Guo ZH, Tao WY, Yang YF, Xu X, Li 555 Y, Wang YH, and Yang L. 2014. TCMSP: a database of systems pharmacology for drug 556 discovery from herbal medicines. Journal of Cheminformatics 6: Artn 13. 
557

558

559

560

561

562

563

564

565

566

567

568

569

570

571

572

573

574

575

576

577

578

579

580

581

582

583

584

585

586

587

588

589

590

591

592

593

594

595

596

DOI:10.1186/1758-2946-6-13

Sacco F, Seelig A, Humphrey SJ, Krahmer N, Volta F, Reggio A, Marchetti P, Gerdes J, and Mann M. 2019. Phosphoproteomics reveals the GSK3-PDX1 axis as a key pathogenic signaling node in diabetic islets. Cell Metabolism 29:1422-1432.e1423. DOI:10.1016/j.cmet.2019.02.012 Shahraki MR, Arab MR, Mirimokaddam E, and Palan MJ. 2007. The effect of Teucrium polium (Calpoureh) on liver function, serum lipids and glucose in diabetic male rats. Iranian Biomedical Journal 11:65-68.

Shannon P, Markiel A, Ozier O, Baliga NS, Wang JT, Ramage D, Amin N, Schwikowski B, and Ideker T. 2003. Cytoscape: A software environment for integrated models of biomolecular interaction networks. Genome Research 13:2498-2504. DOI:10.1101/gr.1239303

Stevens PF. 2017. Angiosperm Phylogeny Website (accessed 18 May 2020).

Szklarczyk D, Gable AL, Lyon D, Junge A, Wyder S, Huerta-Cepas J, Simonovic M, Doncheva NT, Morris JH, Bork P, Jensen LJ, and Mering Christian v. 2018. STRING v11: protein-protein association networks with increased coverage, supporting functional discovery in genome-wide experimental datasets. Nucleic Acids Research 47: D607-D613. DOI:10.1093/nar/gky1131 Tabatabaie PS, and Yazdanparast R. 2017. Teucrium polium extract reverses symptoms of streptozotocin-induced diabetes in rats via rebalancing the Pdx1 and FoxO1 expressions. Biomedicine \& Pharmacotherapy 93:1033-1039. DOI:10.1016/j.biopha.2017.06.082 Turner JV, and Agatonovic-Kustrin S. 2007. 5.29 - In Silico Prediction of Oral Bioavailability. In: Taylor JB, and Triggle DJ, eds. Comprehensive Medicinal Chemistry II. Oxford: Elsevier, 699-724. DOI: 10.1016/b0-08-045044-x/00147-4

Tuzlacı E. 2016. Türkiye Bitkileri Geleneksel Illaç Rehberi. Istanbul: Istanbul Tıp Kitabevleri. Vuylsteke V, Chastain LM, Maggu GA, and Brown C. 2015. Imeglimin: A potential new multitarget drug for type 2 diabetes. Drugs in R\&D 15:227-232. DOI:10.1007/s40268-015-0099-3 Wu Y, Zhang F, Yang K, Fang S, Bu D, Li H, Sun L, Hu H, Gao K, Wang W, Zhou X, Zhao Y, and Chen J. 2018. SymMap: an integrative database of traditional Chinese medicine enhanced by symptom mapping. Nucleic Acids Research 47:D1110-D1117. DOI:10.1093/nar/gky1021 Xiang SY, Zhao J, Lu Y, Chen RM, Wang Y, Chen Y, Long B, Zhu LP, Yao PF, Xu YF, and Chen JH. 2019. Network pharmacology-based identification for therapeutic mechanism of LingGui-Zhu-Gan decoction in the metabolic syndrome induced by antipsychotic drugs. Computers in Biology and Medicine 110:1-7. DOI:10.1016/j.compbiomed.2019.05.007 Yazdanparast R, Esmaeili MA, and Ashrafi Helan J. 2005. Teucrium polium extract effects pancreatic function of streptozotocin diabetic rats: a histopathological examination. Iranian Biomedical Journal 9:81-85.

Zhang RZ, Zhu X, Bai H, and Ning K. 2019. Network pharmacology databases for traditional chinese medicine: review and assessment. Frontiers in Pharmacology 10. ARTN 123 DOI:10.3389/fphar.2019.00123

Zheng Y, Ley SH, and Hu FB. 2018. Global aetiology and epidemiology of type 2 diabetes mellitus and its complications. Nature Reviews Endocrinology 14:88-98.

DOI:10.1038/nrendo.2017.151 


\section{Figure 1}

The scheme for intersection of $T$. polium and type 2 diabetes mellitus (T2DM) targets.

\section{Targets of Teucrium polium 452}


Figure 2

'Compound-Key Target-Pathway' network of T. polium.

Red nodes represent phenolic compounds, green nodes represent terpenoids and pink node represent cyanogenic glycoside. Key targets are given in light blue nodes and pathways are given in dark blue nodes.

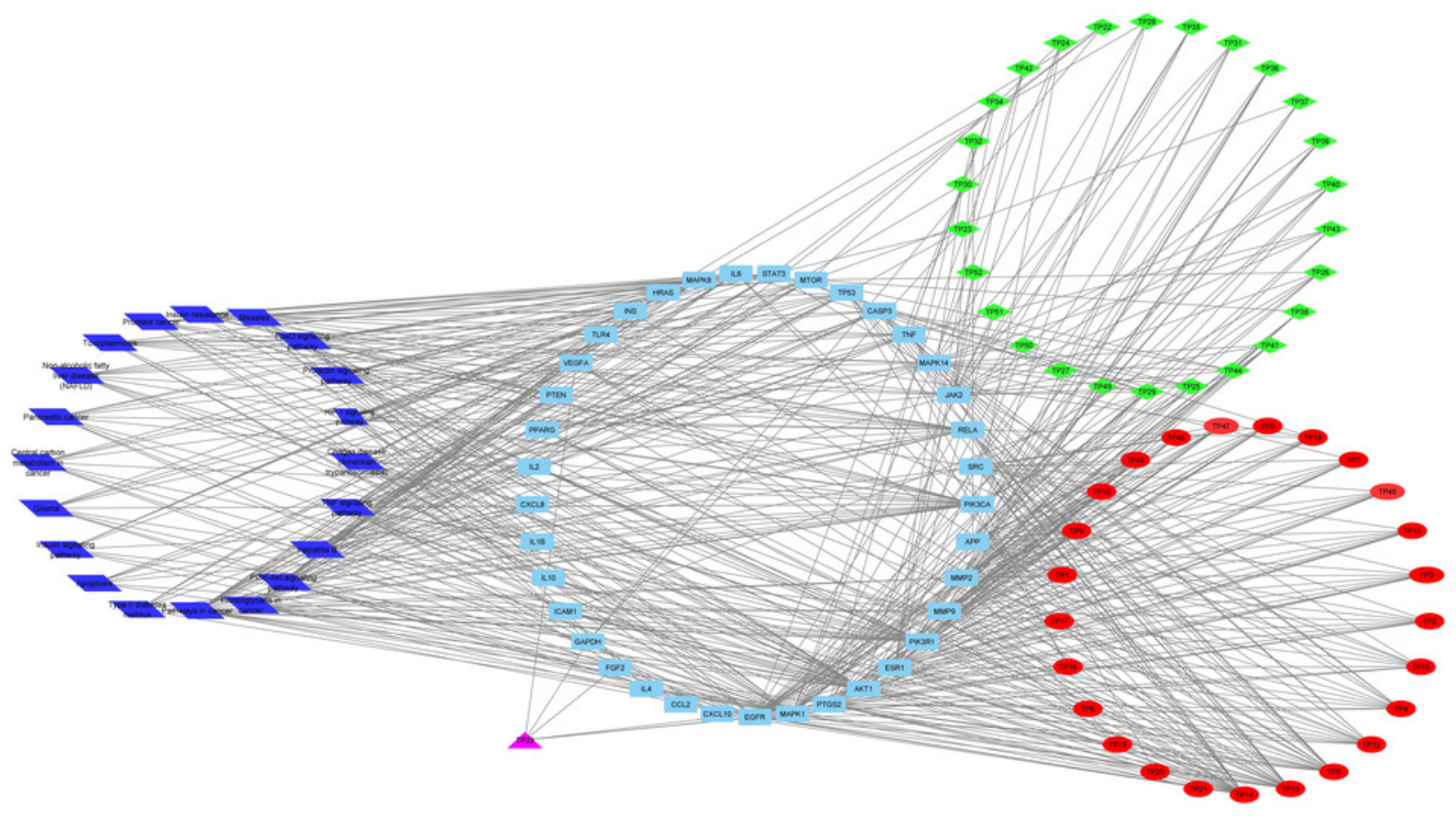


Figure 3

The PPI network of the 37 key targets obtained from STRING v11.

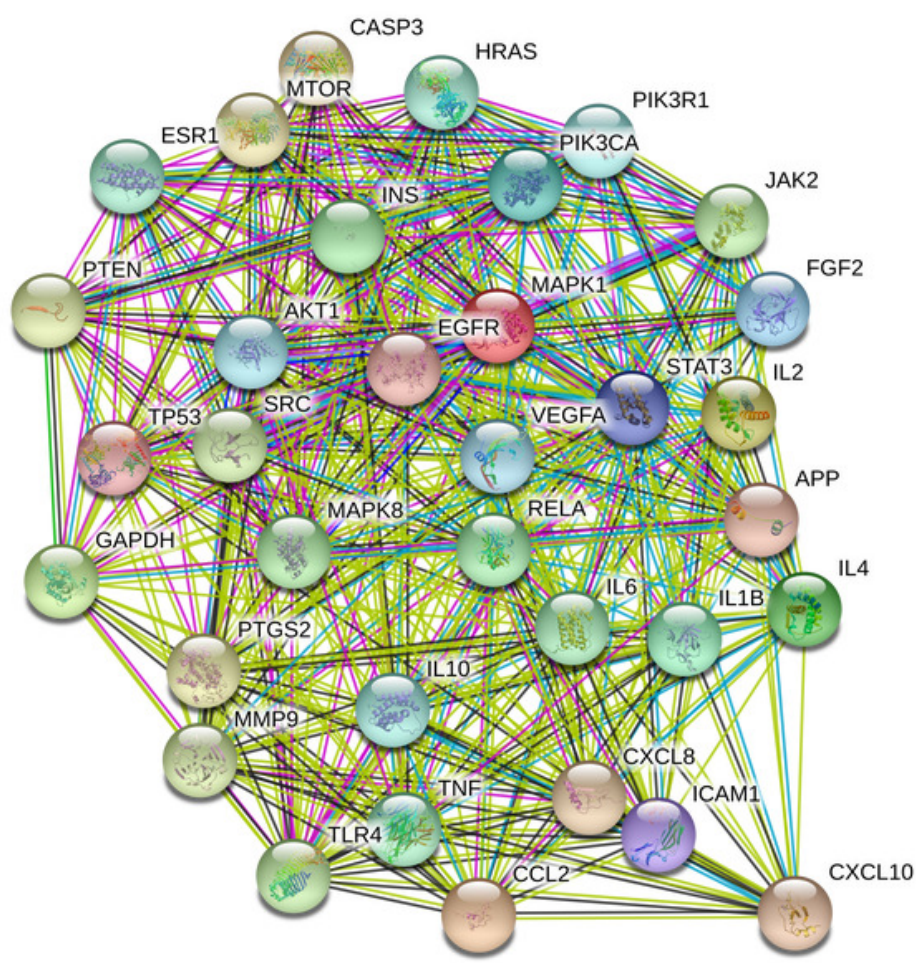


Figure 4

GO gene enrichment analysis for 252 common targets (top 20 results according to the $p$ value). 


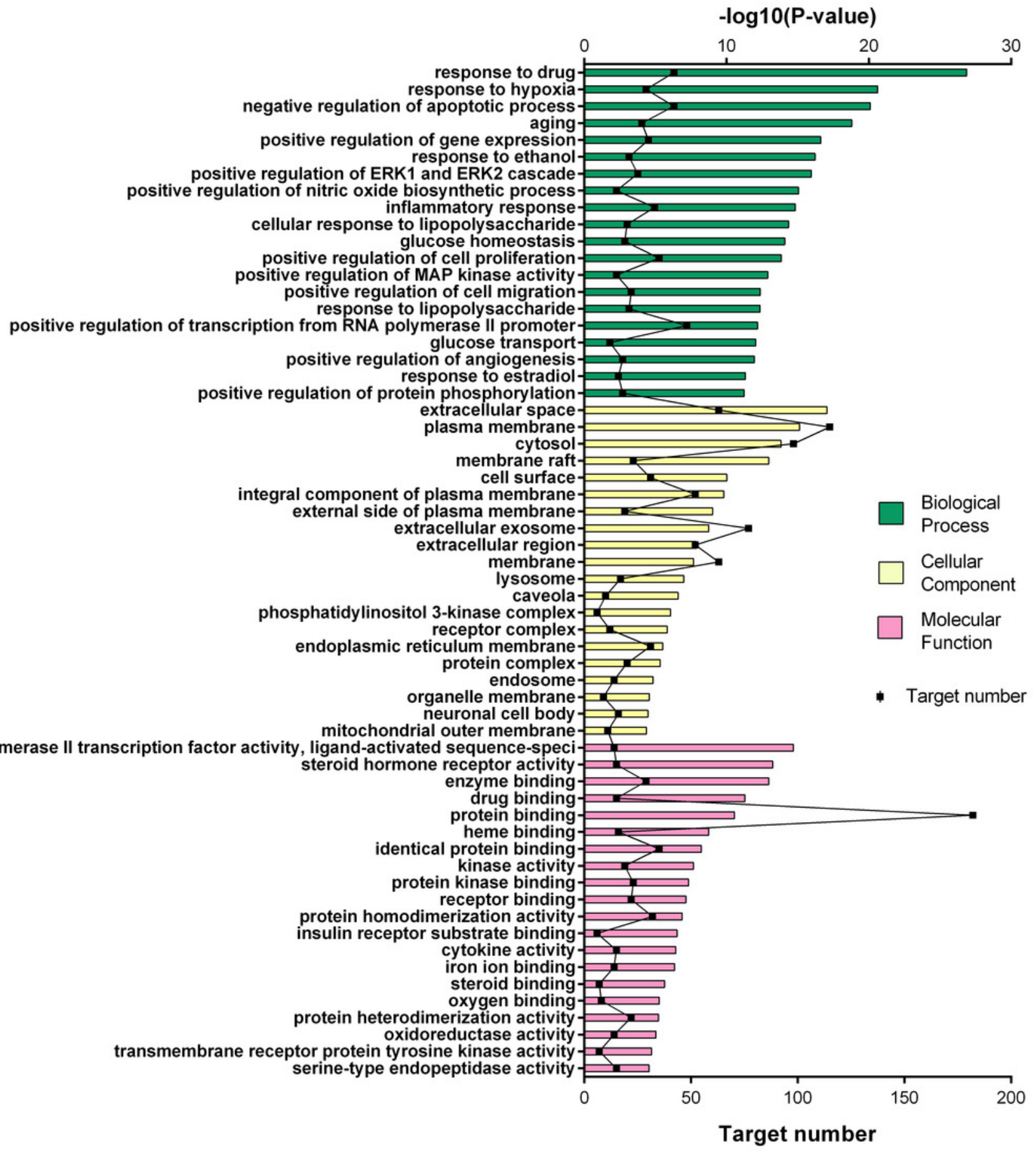


Figure 5

KEGG pathway enrichment results for 252 candidate target genes (top 20 results according to the $p$ value).

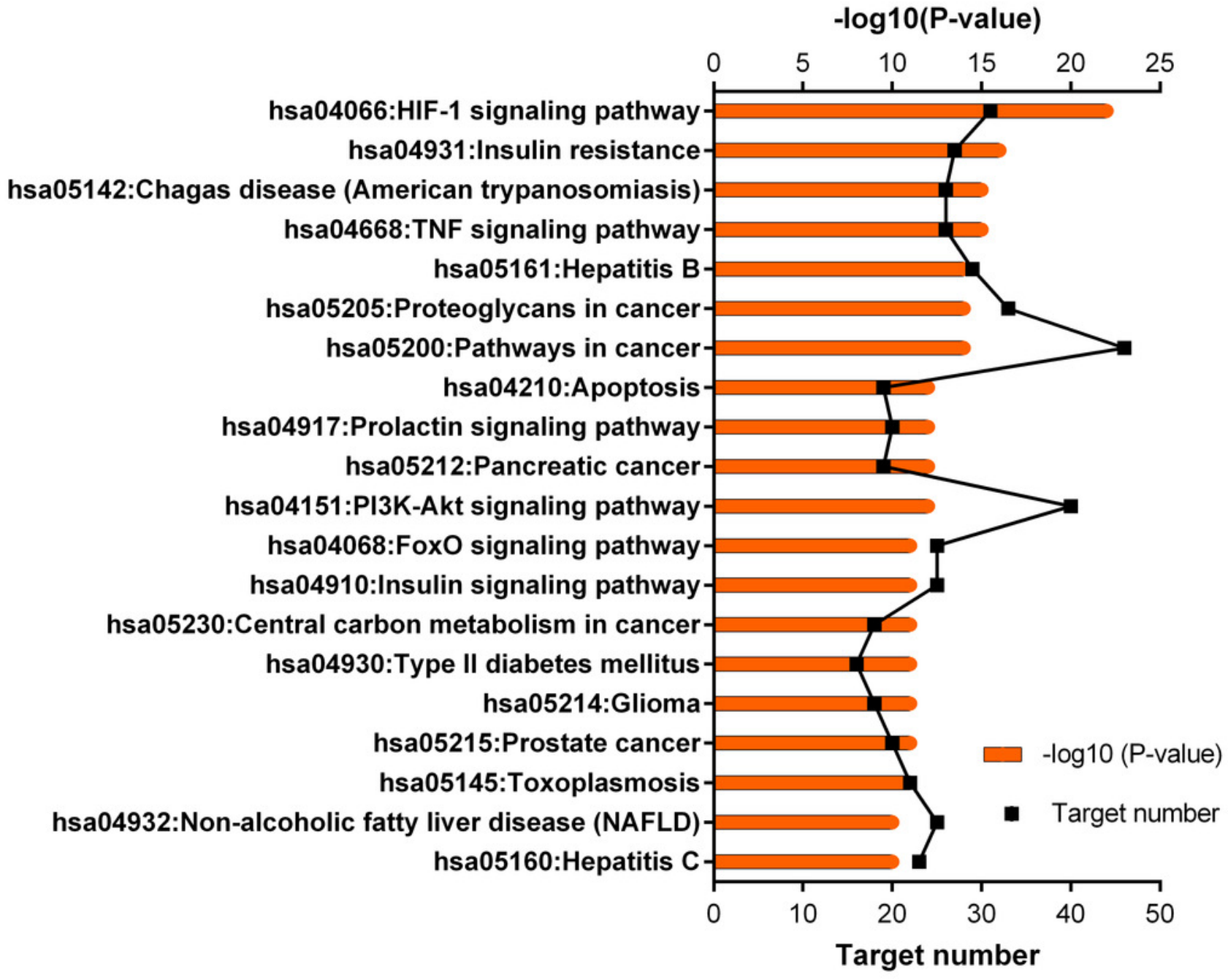




\section{Table $\mathbf{1}$ (on next page)}

The molecular formula and structures of the 52 compounds that used in network pharmacology analysis. 


\begin{tabular}{|c|c|c|c|c|}
\hline No & $\begin{array}{l}\text { Compound } \\
\text { code }\end{array}$ & Compound Name & Formula & Structure \\
\hline 1 & TP1 & 4',7-dimethoxy apigenin & $\mathrm{C}_{17} \mathrm{H}_{14} \mathrm{O}_{5}$ & \\
\hline 2 & $\mathrm{TP} 2$ & 4'-O-methyl luteolin & $\mathrm{C}_{16} \mathrm{H}_{12} \mathrm{O}_{6}$ & \\
\hline 3 & TP3 & 6-hydroxy luteolin & $\mathrm{C}_{15} \mathrm{H}_{10} \mathrm{O}_{7}$ & \\
\hline 4 & ТP4 & Acacetin & $\mathrm{C}_{16} \mathrm{H}_{12} \mathrm{O}_{5}$ & \\
\hline 5 & TP5 & Apigenin & $\mathrm{C}_{15} \mathrm{H}_{10} \mathrm{O}_{5}$ & \\
\hline 6 & ТP6 & Catechin & $\mathrm{C}_{15} \mathrm{H}_{14} \mathrm{O}_{6}$ & \\
\hline 7 & TP7 & Cirsilineol & $\mathrm{C}_{18} \mathrm{H}_{16} \mathrm{O}_{7}$ & \\
\hline 8 & TP8 & Cirsiliol & $\mathrm{C}_{17} \mathrm{H}_{14} \mathrm{O}_{7}$ & \\
\hline 9 & TP9 & Cirsimaritin & $\mathrm{C}_{17} \mathrm{H}_{14} \mathrm{O}_{6}$ & \\
\hline
\end{tabular}


10

TP10 Eupatorin

$\mathrm{C}_{18} \mathrm{H}_{16} \mathrm{O}_{7}$<smiles>COc1cc2oc(-c3ccc(I)c(I)c3)cc(=O)c2c(C)c1OC</smiles>

11 TP11 Isoscutellarein

$\mathrm{C}_{15} \mathrm{H}_{10} \mathrm{O}_{6}$<smiles>Cc1ccc(-c2cc(=O)c3c(Br)cc(C)c(O)c3s2)cc1</smiles>

12 TP12 Jaceosidin

$\mathrm{C}_{17} \mathrm{H}_{14} \mathrm{O}_{7}$

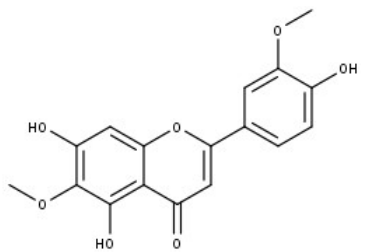

13 TP13 Luteolin

$\mathrm{C}_{15} \mathrm{H}_{10} \mathrm{O}_{6}$

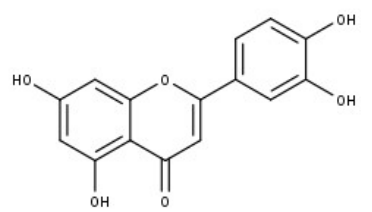

14

TP14 Quercetin

$\mathrm{C}_{15} \mathrm{H}_{10} \mathrm{O}_{7}$

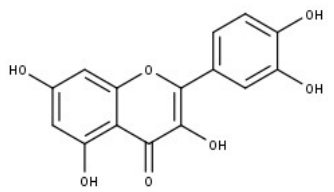

$15 \quad$ TP15 Caffeic acid

$\mathrm{C}_{9} \mathrm{H}_{8} \mathrm{O}_{4}$<smiles>CC(=O)/C=C/c1ccc(C)c(O)c1</smiles>

TP16 Gallic acid

$\mathrm{C}_{7} \mathrm{H}_{6} \mathrm{O}_{5}$<smiles>Cc1cc(C(C)C)cc(C)c1C</smiles>

$17 \quad$ TP17 $p$-Coumaric acid

$\mathrm{C}_{9} \mathrm{H}_{8} \mathrm{O}_{3}$<smiles>C=C(C)C=Cc1ccc(C)cc1</smiles>

TP18 $t$-Ferulic acid

$\mathrm{C}_{10} \mathrm{H}_{10} \mathrm{O}_{4}$<smiles>COc1cc(/C=C/C(C)=O)ccc1O</smiles>

$\mathrm{C}_{8} \mathrm{H}_{8} \mathrm{O}_{4}$<smiles>COc1cc(C(=O)O)ccc1O</smiles>

$\mathrm{C}_{8} \mathrm{H}_{10} \mathrm{O}_{3}$ dihydroxyphenyl)ethanol<smiles>CCCc1ccc(O)c(C)c1</smiles> 
21

22

23

24

TP24

TP23

TP22

$4 \alpha-[(\beta-\mathrm{D}-$

glucopyranosyloxy)methyl]$5 \alpha$-(2-hydroxyethyl)-3-

methylcyclopent-2-en-1-one

24

25

TP25 Capitatin

$5 \alpha-[2-(\beta-\mathrm{D}-$

glucopyranosyloxy)ethyl]-4 $\alpha$ -

hydroxymethyl-3-

methylcyclopent-2-en-1-one

20-O-acetyl-teucrasiatin

$\mathrm{C}_{24} \mathrm{H}_{30} \mathrm{O}_{8}$

$\mathrm{C}_{24} \mathrm{H}_{28} \mathrm{O}_{9}$

$\mathrm{C}_{22} \mathrm{H}_{24} \mathrm{O}_{8}$

$\mathrm{C}_{22} \mathrm{H}_{28} \mathrm{O}_{6}$

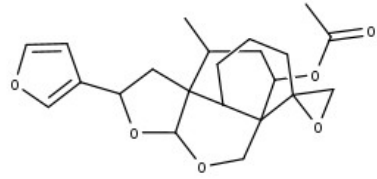

28

29
TP28 Teupolin VII

TP26 Clerodane-6,7-dione

TP27 Teubutilin A

TP29 Teupolin VIII
$\mathrm{C}_{8} \mathrm{H}_{10} \mathrm{O}_{2}$

$\mathrm{C}_{15} \mathrm{H}_{24} \mathrm{O}_{8}$

$\mathrm{C}_{15} \mathrm{H}_{24} \mathrm{O}_{8}$
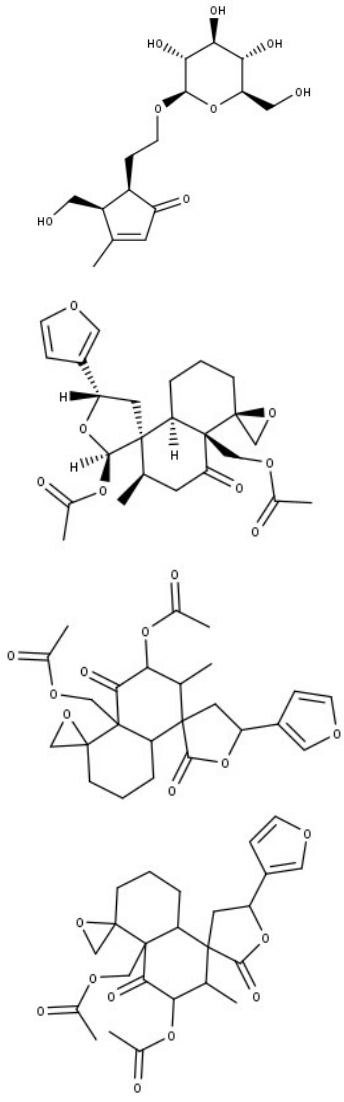

27

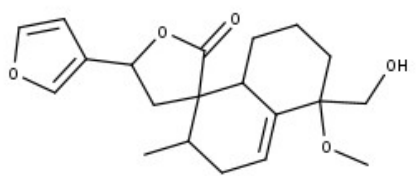

$\mathrm{C}_{19} \mathrm{H}_{24} \mathrm{O}_{5}$ 
(1R, 4S, 10R) 10,11-dimethyl- $\quad \mathrm{C}_{12} \mathrm{H}_{18} \mathrm{O}_{3}$ dicyclohex-5(6)-en-1,4-diol-7one

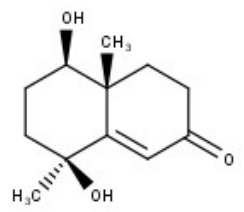

31

TP31 (1R,6R,7R,8S,11R)-1,6-

$\mathrm{C}_{15} \mathrm{H}_{22} \mathrm{O}_{4}$ dihydroxy-4,11-dimethylgermacran-4(5), 10(14)-dien8,12-olide

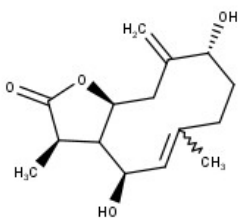

32 TP32 (10R,1R,4S,5S,6R,7S)-4,10die-poxygermacran-6-ol

$\mathrm{C}_{15} \mathrm{H}_{26} \mathrm{O}_{3}$

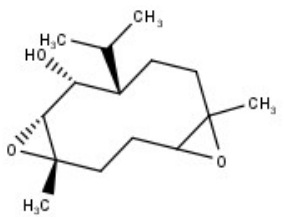

$\mathrm{C}_{14} \mathrm{H}_{17} \mathrm{NO}_{6}$<smiles>C#CC(OC1NC(CO)[C@@H](O)[C@H](C)[C@H]1C)c1ccccc1</smiles>

$\mathrm{C}_{12} \mathrm{H}_{18} \mathrm{O}_{2}$<smiles>C[C@@H]1CC[C@@H](O)C2=CC(=O)CC[C@@]21C</smiles>

$\mathrm{C}_{15} \mathrm{H}_{24} \mathrm{O}_{3}$ 10(14)-en-6 $\beta$-ol-1-one

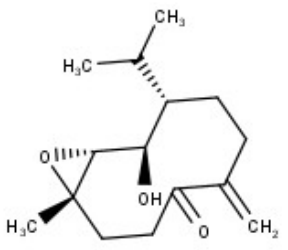

$4 \beta, 5 \alpha$-Epoxy- $7 \alpha \mathrm{H}$-germacr10(14)-en, $1 \beta$ hydroperoxyl, $6 \beta$-ol

$\mathrm{C}_{15} \mathrm{H}_{26} \mathrm{O}_{4}$

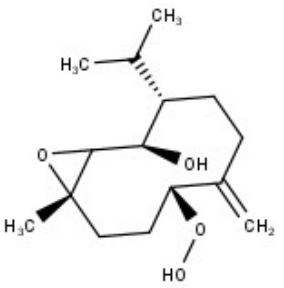

$4 \beta, 5 \beta$-Epoxy- $7 \alpha \mathrm{H}$-germacr10(14)-en, $1 \beta$ -

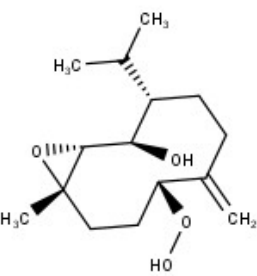


$4 \alpha, 5 \beta$-epoxy- $7 \alpha \mathrm{H}$-germacr-

$\mathrm{C}_{15} \mathrm{H}_{26} \mathrm{O}_{4}$ 10(14)-en, $1 \beta$ -

hydroperoxyl, $6 \alpha-\mathrm{ol}$

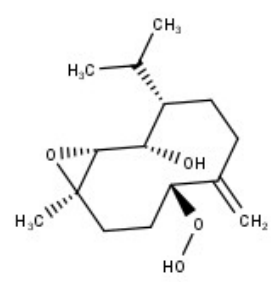

39

TP39 $10 \alpha, 1 \beta ; 4 \beta, 5 \alpha$-diepoxy- $7 \alpha \mathrm{H}$ -

$\mathrm{C}_{15} \mathrm{H}_{26} \mathrm{O}_{3}$ germacrm-6-ol

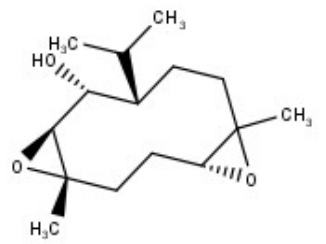

40

TP40 Teucladiol

$\mathrm{C}_{15} \mathrm{H}_{26} \mathrm{O}_{2}$

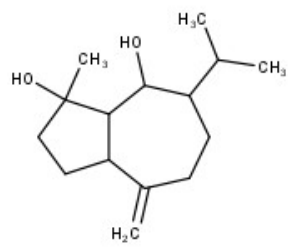

41

TP41 $4 \beta, 6 \beta$-dihydroxy- $1 \alpha, 5 \beta(\mathrm{H})$ guai-9-ene

$\mathrm{C}_{15} \mathrm{H}_{26} \mathrm{O}_{2}$

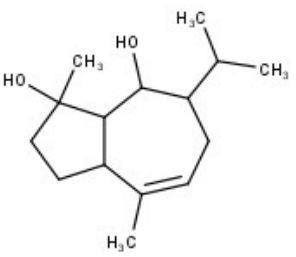

42

TP42 Oplopanone

$\mathrm{C}_{15} \mathrm{H}_{26} \mathrm{O}_{2}$

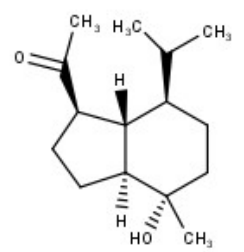

43

TP43 Oxyphyllenodiol A

$\mathrm{C}_{14} \mathrm{H}_{22} \mathrm{O}_{3}$<smiles>CC1CC2C3=C(CCC2(C)O)C(=O)CCC31</smiles>

44

TP44 Arteincultone

$\mathrm{C}_{15} \mathrm{H}_{24} \mathrm{O}_{4}$<smiles>[2H][C@@](C)(/C=C/C(=O)[C@H](C)C1CC[C@@](C)(C=C)O1)OC</smiles>

45

TP45 Ladanein

$\mathrm{C}_{17} \mathrm{H}_{14} \mathrm{O}_{6}$<smiles>COc1ccc(-c2cc(=O)c3c(O)c(O)c(OC)cc3o2)cc1</smiles> 
$\mathrm{C}_{18} \mathrm{H}_{16} \mathrm{O}_{6}$

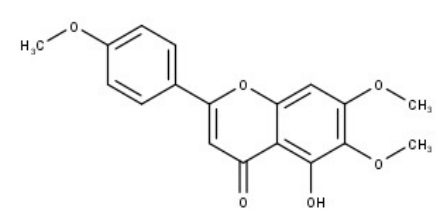

47

TP47

5,3',4'- trihydroxy-3,7dimethoxyflavone

$\mathrm{C}_{17} \mathrm{H}_{14} \mathrm{O}_{7}$

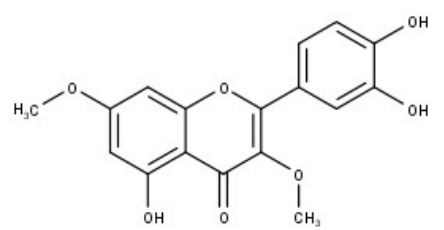

48

TP48 Jaranol

$\mathrm{C}_{17} \mathrm{H}_{14} \mathrm{O}_{6}$<smiles>COc1cc(C)c2c(=O)c(O)c(-c3ccc(I)cc3)oc2c1</smiles>

49

TP49 $\quad \beta$-eudesmol

$\mathrm{C}_{15} \mathrm{H}_{26} \mathrm{O}$<smiles>C=C1CCC[C@]2(C)CC[C@](C)(C(C)(C)O)C[C@]12C</smiles>

50

TP50 $\quad \alpha$-Cadinol

$\mathrm{C}_{15} \mathrm{H}_{26} \mathrm{O}$<smiles>CC1=CC2C(CC1)C(C)(O)CC[C@@H]2C(C)C</smiles>

51

TP51 7-epi-Eudesm-4(15)-ene$1 \beta, 6 \alpha$-diol

$\mathrm{C}_{15} \mathrm{H}_{26} \mathrm{O}_{2}$

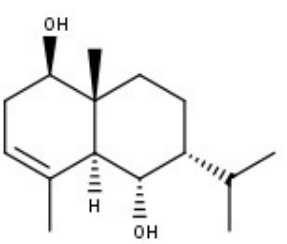

52

TP52 7-epi-Eudesm-4(15)-ene-

$\mathrm{C}_{15} \mathrm{H}_{26} \mathrm{O}_{2}$

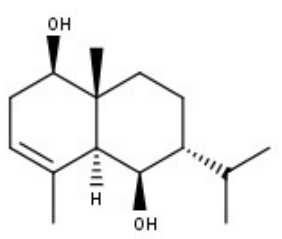

1 


\section{Table 2 (on next page)}

KEGG pathway enrichment results for 252 common targets together with the key targets involved. 


\begin{tabular}{|c|c|c|c|}
\hline No & Pathway Name & Key Target & Nodes \\
\hline 1 & HIF-1 signaling pathway & $\begin{array}{l}\text { AKT1, RELA, EGFR, GAPDH, INS, IL6, } \\
\text { MTOR, MAPK1, PIK3CA, PIK3R1, } \\
\text { STAT3, TLR4, VEGFA }\end{array}$ & 13 \\
\hline 2 & Insulin resistance & $\begin{array}{l}\text { AKT1, RELA, INS, IL6, MTOR, } \\
\text { MAPK8, PTEN, PIK3CA, PIK3R1, } \\
\text { STAT3, TNF }\end{array}$ & 11 \\
\hline 3 & Chagas disease (American trypanosomiasis) & $\begin{array}{l}\text { AKT1, CCL2, CXCL8, RELA, IL1B, } \\
\text { IL10, IL2, IL6, MAPK1, MAPK14, } \\
\text { MAPK8, PIK3CA, PIK3R1, TLR4, TNF }\end{array}$ & 15 \\
\hline 4 & TNF signaling pathway & $\begin{array}{l}\text { AKT1, CCL2, CXCL10, RELA, CASP3, } \\
\text { ICAM1, IL1B, IL6, MMP9, MAPK1, } \\
\text { MAPK14, MAPK8, PIK3CA, PIK3R1, } \\
\text { PTGS2, TNF }\end{array}$ & 16 \\
\hline 5 & Hepatitis B & $\begin{array}{l}\text { AKT1, CXCL8, HRAS, RELA, SRC, } \\
\text { CASP3, IL6, MMP9, MAPK1, } \\
\text { MAPK8, PTEN, PIK3CA, PIK3R1, } \\
\text { STAT3, TLR4, TNF, TP53 }\end{array}$ & 17 \\
\hline 6 & Proteoglycans in cancer & $\begin{array}{l}\text { AKT1, HRAS, SRC, CASP3, EGFR, } \\
\text { ESR1, FGF2, MMP2, MMP9, MTOR, } \\
\text { MAPK1, MAPK14, PIK3CA, PIK3R1, } \\
\text { STAT3, TLR4, TNF, TP53, VEGFA }\end{array}$ & 19 \\
\hline 7 & Pathways in cancer & $\begin{array}{l}\text { AKT1, CXCL8, HRAS, RELA, CASP3, } \\
\text { EGFR, FGF2, IL6, MMP2, MMP9, } \\
\text { MTOR, MAPK1, MAPK8, PPARG, } \\
\text { PTEN, PIK3CA, PIK3R1, PTG2, } \\
\text { STAT3, TP53, VEGFA }\end{array}$ & 21 \\
\hline 8 & Apoptosis & $\begin{array}{l}\text { AKT1, RELA, CASP3, PIK3CA, } \\
\text { PIK3R1, TNF, TP53 }\end{array}$ & 7 \\
\hline 9 & Prolactin signaling pathway & $\begin{array}{l}\text { AKT1, HRAS, JAK2, RELA, SRC, ESR1, } \\
\text { INS, MAPK1, MAPK14, MAPK8, } \\
\text { PIK3CA, PIK3R1, STAT3 }\end{array}$ & 13 \\
\hline 10 & Pancreatic cancer & $\begin{array}{l}\text { AKT1, RELA, EGFR, MAPK1, MAPK8, } \\
\text { PIK3CA, PIK3R1, STAT3, TP53, } \\
\text { VEGFA }\end{array}$ & 10 \\
\hline 11 & PI3K-Akt signaling pathway & $\begin{array}{l}\text { AKT1, HRAS, JAK2, RELA, EGFR, } \\
\text { EGFR, INS, IL2, IL4, IL6, MTOR, } \\
\text { MAPK1, PTEN, PIK3CA, PIK3R1, } \\
\text { TLR4, TP53, VEGFA }\end{array}$ & 18 \\
\hline 12 & FoxO signaling pathway & $\begin{array}{l}\text { AKT1, HRAS, EGFR, INS, IL10, IL6, } \\
\text { MAPK1, MAPK14, MAPK8, PTEN, } \\
\text { PIK3CA, PIK3R1, STAT3 }\end{array}$ & 13 \\
\hline 13 & Insulin signaling pathway & $\begin{array}{l}\text { AKT1, HRAS, INS, MTOR, MAPK1, } \\
\text { MAPK8, PIK3CA, PIK3R1 }\end{array}$ & 8 \\
\hline 14 & Central carbon metabolism in cancer & $\begin{array}{l}\text { AKT1, HRAS, EGFR, MTOR, MAPK1, } \\
\text { PTEN, PIK3CA, PIK3R1, TP53 }\end{array}$ & 9 \\
\hline 15 & Type II diabetes mellitus & INS, MTOR, MAPK1, MAPK8, & 7 \\
\hline
\end{tabular}




\begin{tabular}{|c|c|c|c|}
\hline & & PIK3CA, PIK3R1, TNF & \\
\hline 16 & Glioma & $\begin{array}{l}\text { AKT1, HRAS, EGFR, MTOR, MAPK1, } \\
\text { PTEN, PIK3CA, PIK3R1, TP53 }\end{array}$ & 9 \\
\hline 17 & Prostate cancer & $\begin{array}{l}\text { AKT1, HRAS, RELA, EGFR, INS, } \\
\text { MTOR, MAPK1, PTEN, PIK3CA, } \\
\text { PIK3R1, TP53 }\end{array}$ & 11 \\
\hline 18 & Toxoplasmosis & $\begin{array}{l}\text { AKT1, JAK2, RELA, CASP3, IL10, } \\
\text { MAPK1, MAPK14, MAPK8, STAT3, } \\
\text { TLR4, TNF }\end{array}$ & 11 \\
\hline 19 & Non-alcoholic fatty liver disease (NAFLD) & $\begin{array}{l}\text { AKT1, CXCL8, RELA, CASP3, INS, } \\
\text { IL1B, IL6, MAPK8, PIK3CA, PIK3R1, } \\
\text { TNF }\end{array}$ & 11 \\
\hline 20 & Measles & $\begin{array}{l}\text { AKT1, JAK2, RELA, IL1B, IL2, IL4, IL6, } \\
\text { PIK3CA, PIK3R1, STAT3, TLR4, TP53 }\end{array}$ & 12 \\
\hline
\end{tabular}

1 